\title{
Short-term Breakdown and Long-term Failure in Nanodielectrics: A Review
}

\author{
Shengtao $\mathrm{Li}^{1}$, Guilai Yin ${ }^{1}$, G. Chen ${ }^{2}$, Jianying $\mathrm{Li}^{1}$, Suna Bai ${ }^{1}$ \\ Lisheng Zhong ${ }^{1}$, Yunxia Zhang ${ }^{1}$, and Qingquan Lei ${ }^{1,3}$ \\ ${ }^{1}$ State Key Laboratory of Electrical Insulation and Power Equipment, \\ Xi'an Jiaotong University, Xi'an, Shaanxi, 710049, China \\ ${ }^{2}$ School of Electronics and Computer Science, University of Southampton, Southampton SO17 1BJ, UK \\ ${ }^{3}$ Key Laboratory of Engineering Dielectric and Its Application, Ministry of Education, \\ Harbin University of Science and Technology, Harbin, Heilongjiang, 150040, China
}

\begin{abstract}
Nanodielectrics, which are concentrated in polymer matrix incorporating nanofillers, have received considerable attention due to their potential benefits as dielectrics. In this paper, short-term breakdown and long-term failure properties of nanodielectrics have been reviewed. The characteristics of polymer matrix, types of nanoparticle and its content, and waveforms of the applied voltage are fully evaluated. In order to effectively comment on the published experimental data, a ratio $k$ has been proposed to compare the electric properties of the nanodielectrics with the matrix and assess the effect for nanoparticles doping. There is evidence that the short-term breakdown properties of nanodielectrics show a strong dependence on the applied voltage waveforms. The polarity and the cohesive energy density (CED) of polymer matrix have a dramatic influence on the properties of nanodielectrics. Nanoparticle doped composites show a positive effect on the long-term failure properties, such as ageing resistance and partial discharge (PD) properties of nanocomposites are superior than microcomposites and the matrix. The larger the dielectric constant and CED of the matrix become, the more significant improvements in long-term performance appear. Based on the reported experimental results, we also present our understandings and propose some suggestions for further work.
\end{abstract}

Index Terms - Nanodielectric, short-term breakdown, long-term degradation, cohesive energy density.

\section{INTRODUCTION}

NANOCOMPOSITES present a series of unique properties, such as electrics [1-3], mechanics [4-5], optics [6-7] and magnetics [8,9], due to nanoparticles with a giant specific surface area, quantum size effect and the special interface between particles and polymer matrix. Nanodielectrics have attracted a great attention since the first experimental data were reported publicly in 2002 [1011]. The current research is concentrated on the short-term breakdown and the long-term failure of epoxy and other polymer matrix with inorganic nanoparticles added.

Short-term breakdown properties mainly include surface flashover and electric breakdown. The transport processes of electrons under low and high electrical field, which are affected by the quantum size effect of nanoparticles and the

Manuscript received on 2 February 2010, in final form 26 May 2010. interface around the nanoparticles, are hard to describe clearly at the present stage but important for understanding the mechanisms of short-term breakdown. The interface is widely recognized to play a key role in determining the short-term breakdown properties, its detailed structure and properties need to firstly be understood. Efforts have been made over the years on the possible interaction between polymeric matrix and nanoparticles. It has been known that the polarity of polymer, the type and the surface states of nanoparticles have a combinative influence on the interface. Roy and Nelson have discussed the role of interface in polymer nanocomposites [12]. A multi-core model of the interface has been constructed by Tanaka [13] and Wilke and Wen have proposed an organic and inorganic composites hybrid network model [14]. More research is required.

The homogeneous distribution of nanoparticles in polymer matrix is another problem of the interface research. 
Nanoparticles are dispersed in matrix chiefly by shear force diffusion and chemical modification in the majority of experiments. The viscosity of the matrix is an important factor for shear force diffusion. Chemical modification will alter the surface states of nanoparticles (such as silane couplings pretreatment) in order to increase the electrostatic force between fillers and matrix. In different production processes, the interface is in various thickness and layer numbers. In this way, the results of nanodielectric properties have little comparability and poor reproducibility, which has been confirmed by the reported data. Some groups reported that the nanoparticles can help to improve the short-term performance [13, 15-16], while others experiments observed the opposite results [17], indicating that the role of nanoparticles in matrix is still unclear in the short-term breakdown. However, the long-term performances, such as PD resistance and ageing resistance, are superior to the matrix. Based on the published data, short-term breakdown properties and long-term failure properties of spherical inorganic particles in polymeric matrices nanodielectrics are reviewed in this paper. It includes five parts. The first part describes the temporal and spatial hierarchy between ageing, degradation and breakdown in dielectrics. Surface flashover characteristics and electric breakdown properties of nanodielectrics belong to the short-term breakdown, which are commented in part two. Part three consists of long-term failure behaviors. The properties of electrical ageing and PD behavior are evaluated in this section. The fourth section is discussion, in which we will present our understandings on the reported results of nanodielectrics. Summary and suggestions for further work are contained in the final section.

\section{THE SPATIO-TEMPORAL RELATION BETWEEN AGEING, DEGRADATION AND BREAKDOWN OF DIELECTRICS}

Under a variety of field stresses, the breakdown suffered by dielectric material presents a very strong time-dependent relationship, so it can be divided into five or more kinds by breakdown speed as shown in Table 1 [18]. The three formers are known as the short-term breakdown, the others are degradation [19-20].

Table 1. Different electrical breakdown in time scale.

\begin{tabular}{|c|c|c|c|c|c|}
\hline & $\begin{array}{c}\text { Electric } \\
\text { breakdown }\end{array}$ & $\begin{array}{c}\text { Thermal } \\
\text { breakdown }\end{array}$ & $\begin{array}{c}\text { Electro- } \\
\text { mechanical } \\
\text { breakdown }\end{array}$ & $\begin{array}{l}\text { PD and } \\
\text { Electrical } \\
\text { trees }\end{array}$ & $\begin{array}{c}\text { Water } \\
\text { trees }\end{array}$ \\
\cline { 2 - 6 } & \multicolumn{4}{|c|}{ Short-term breakdown } & \multicolumn{2}{|c|}{$\begin{array}{c}\text { Long-term } \\
\text { failure }\end{array}$} \\
\hline $\begin{array}{c}\text { The time of } \\
\text { breakdown }\end{array}$ & $10^{-9}-10^{-6} \mathrm{~s}$ & $10^{-7}-10^{-3} \mathrm{~s}$ & $10^{-6}-10^{-3} \mathrm{~s}$ & $10^{-2}-10^{7} \mathrm{~s}$ & $\mathrm{hrs}-\mathrm{yrs}$ \\
\hline
\end{tabular}

Short-term breakdown shows a very strong dependence on the electrode distance $(d)$. With the $d$ decreasing, breakdowns of solid dielectrics are thermal breakdown $(\mathrm{mm}-\mathrm{cm})$, electron impact ionization breakdown $(\mu \mathrm{m}-$ $\mathrm{mm}$ ) and Fowler-Nordheim electron emission breakdown (1-100 nm) [20-21]. Similar relationships in space dimension could also be seen for short-term breakdown of gas and liquid dielectrics.

Although the time scale of breakdown in gas, liquid and solid dielectrics is $1 \mu \mathrm{s}-1 \mathrm{~ms}$, several $\mu$ s to tens of ms and dozens to hundreds of minutes, respectively, the short-term breakdown or the long-term degradation of gas, liquid and solid dielectrics shows a very similar layers development structure.

Significant time hierarchy and space dimension were found in the ageing, degradation and breakdown of solid dielectric materials [22]. The characteristics of ageing include three aspects: aging always starts in mesoscopic scale and hard to observe directly; it is a continuous process in whole service life and exists at everywhere in the dielectric; it may decrease the system mean time between failures (MTBF), but may not lower the breakdown voltage. For degradation, it also shows three distinctive features: degradation always occurs in micrographic scale and could be observed directly, such as electrical trees; it happens in some places of the material and develops slowly from seconds to months; it can decrease both the MTBF and breakdown voltage. Breakdown (BD) is a disaster for dielectric. It starts from a void in macroscopic scale somewhere in dielectric. The process is very fast $(<<1 \mathrm{~s})$ at only one location, then the dielectric could not be used anymore [18].

A general description of the space dimension of process of aging, degradation and breakdown in solid dielectric is as follows. Under the field stress, diameter of about $10 \mathrm{~nm}$ nanohole appears in the insulation without defect initially. With the growth of nanohole, PD occurs in it. Electrical tree grows continuously in the surrounding polymer region until it spreads through the insulation between the electrodes and then breakdown takes place [22-23].

The characteristics of tree growth and final breakdown in solid dielectrics are relatively clear. How are the nanoholes formed in dielectric materials is currently one of the hotspots in dielectric research. Ageing processes and mechanisms in mesoscopic scale can be described by three theoretical models: the kinetic model suggested by Lewis [24-32]; the space-charge life model developed by Dissado and Montanari [33-38] and thermodynamic model of molecular presented by Crine $[21,39-40]$. Basic descriptions of phenomenon in mesoscopic scale are as follows. The breaking and rearrangement of molecular bonds caused by field and mechanical stresses, affects the existence of nanohole and low density areas (LDA). Then the number of nanoholes develops continuously in LDAs, which are reflected by meteorological ageing phenomenon at the same time. More LDAs appear, thermo-electrons inject and discharge produced in LDAs leading to an increase in local conductivity, these all bring the final breakdown. 


\section{THE PROPERTIES OF SHORT-TERM BREAKDOWN IN NANODIELECTRICS}

\subsection{SURFACE FLASHOVER CHARACTERISTICS OF NANODIELECTRIC IN VACUUM}

Surface flashover of dielectric in vacuum is a typical BD at material surface. It depends on many parameters, such as the waveform of the applied voltage, profile of the insulator, bulk material, surface condition of insulator, and structure of electrodes and so on [41]. Since the surface flashover voltage of dielectric material in vacuum is far lower than the breakdown voltage of vacuum or the bulk, many failures in high electric devices were caused by surface flashover of insulator. In order to improve the surface flashover voltage of insulator in vacuum, nanoparticles and microparticles as dopants added into polymer matrix were considered and new traps could be introduced into the polymer. Type, quantity and distribution of traps will be altered in material surface. It is useful to improve the flashover voltage of dielectric material. Some works have been done in epoxy resin (EP) [42-50].

In order to effectively review the published data, a ratio $k_{1}$, which is defined as the flashover voltage of composite in vacuum divided the flashover voltage of polymer matrix in vacuum, is introduced in this paper.

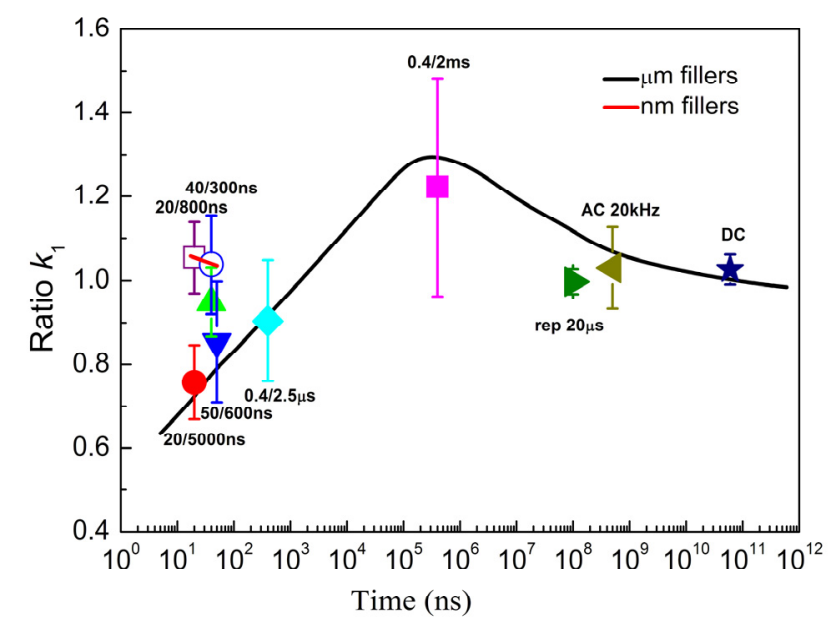

Figure 1. The flashover properties of composites under various applied voltage waveform, ( $>$ from [42, 43], $>$ from [42, 43], $\star$ from [42, 43], $\checkmark$ from [44], $\triangle$ from [45], $\square$ from [46], $\bigcirc$ from [45, 47], untreated; $\checkmark$ from [48], $\nabla$ from [49], $\square$ from [50]. ) Nanofillers were treated in $[48,49,50]$ while untreated in others.

Figure 1 shows the flashover properties of microdielectric and nanodielectric at various applied voltage waveforms. It apparently indicates that the flashover voltage strongly depends on the waveform of the applied voltage. For microdielectric, when pulse rise time of applied voltage is shorter than $1 \mu \mathrm{s}$, microparticles reduce the flashover voltage and the ratio $k_{1}$ is lower than unit. When the pulse rise time is over $1 \mu \mathrm{s}$, microparticles present a positive effect on improving the flashover voltage and the ratio $k_{1}$ is above unit. However, the flashover voltage of nanodielectric has a slight improvement under the pulse rise time of applied voltage lower than $1 \mu \mathrm{s}$. No experimental data is available in a longer time scale. More work should be done on the flashover breakdown of nanodielectrics in vacuum under long impulse waveform voltage. The reason for the effect of the applied voltage waveform on the ratio $k_{1}$ is unclear.

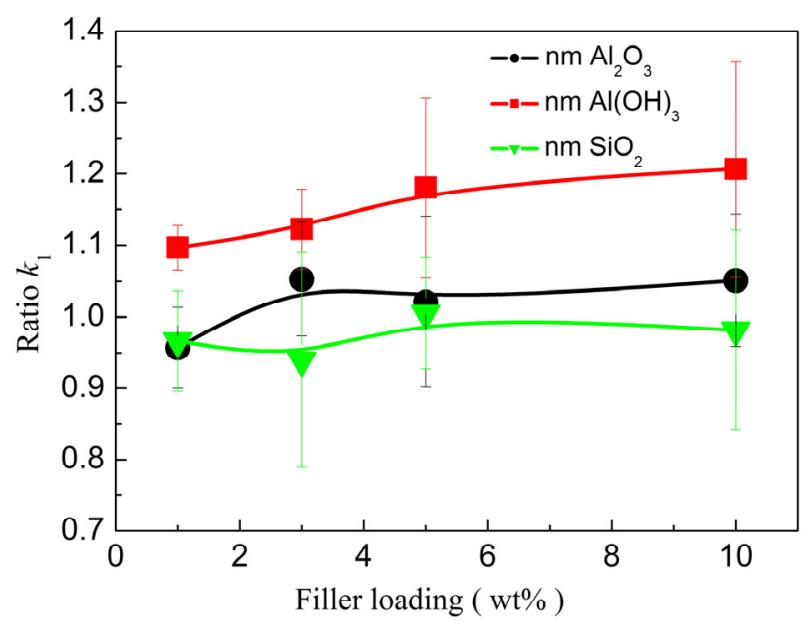

Figure 2. Flashover properties versus nanofillers loading, impulse waveform is $40 \mathrm{~ns} / 200 \mathrm{~ns}$, ( from [45, 47, 49], from[45, 47, 50],

$\nabla$ from $[45,47])$. Nanofillers were treated in $[49,50]$ while untreated in others.

The influence of inorganic nanoparticles on surface flashover of composite is also reviewed here and the results are shown in Figure 2. The information that can be extracted from Figure 2 is that the flashover property of nano $\mathrm{Al}(\mathrm{OH})_{3} / \mathrm{EP}$ composite is superior to pure EP with about $10 \% \sim 20 \%$ higher surface flashover voltage, while the results of nano $\mathrm{SiO}_{2} / \mathrm{EP}$ composite are opposite. For nano $\mathrm{Al}_{2} \mathrm{O}_{3} / \mathrm{EP}$ composite, the surface flashover voltage is lower than that of pure EP when the content is less than $2 \%$ and then increases slowly with the content. Apparently, nanofillers with various dielectric constant exhibited different surface flashover performances. It is generally recognized that the type and the density of traps in material influence the surface flashover properties. Some evidences indicated that new traps with different levels were introduced into composites by doping particles with various dielectric constant [49]. Thus, ratio $k_{1}$ dependence of dielectric constant of particles is associated with the new traps.

The role of traps during the flashover growing was emphasized [51], deep traps can restrain the surface flashover occurring while shallow traps are beneficial for surface flashover. When oxide fillers are doped into polymer matrix, there are two possible cases of change in trap distribution [51]. Nanofillers can introduce deep traps into material whereas mircofillers bring shallow traps $[49-50,52]$.That is to say, theoretically, it can improve the surface flashover voltage by optimizing the proportion of micro and nano particles co-doped. The 
experimental results [52] prove the point and it has been found that the surface flashover properties of nano-andmicro-particles mixture composite (NMMC) is superior to nanocomposite and microcomposite as shown in Figure 3.

It can be seen from Figure 3a that, with microparticles doping, surface flashover voltage does not perform well. The surface flashover voltage of microcomposite decreases firstly and then increases, it reaches to the minimum point at $20 \%$ microparticles doping. This is likely due to the shallow traps introduced by the microparticles. It is known that weak static electric fields exist at the interface between microparticles and epoxy resin. Microparticles introduce shallow traps which contribute a lot to the flashover [51]. Considering an idealized situation where all the spherical shaped particles are assumed to sit on the eight corners of a cube, it is possible to calculate the separation distance between adjacent particles. For $1 \mu \mathrm{m}$ diameter particles, percolation occurs at about $20 \%$ content. "Interaction zone" overlap between two neighbor particles, which leads to the density of shallow traps decreasing when the content of micro-particles was over $20 \%$. For nanocomposites, the

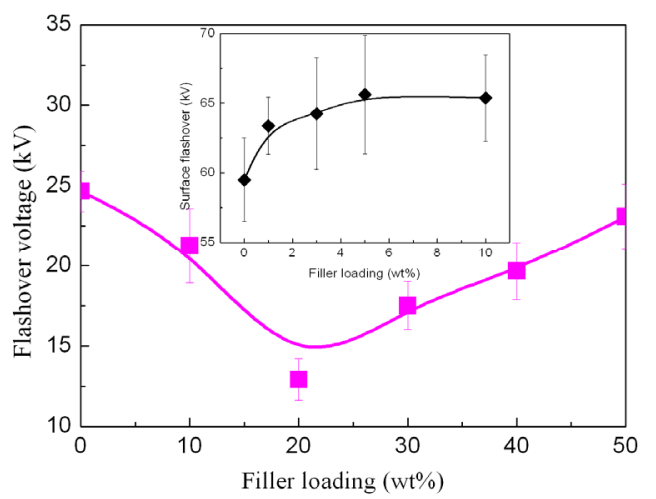

(a)

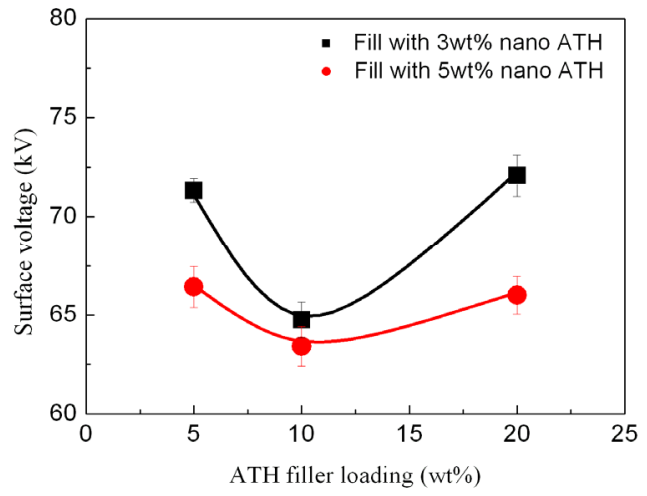

(b)

Figure 3. (a) Flashover voltage versus micro- $\mathrm{Al}(\mathrm{OH})_{3}$ loading with average diameter of $1 \mu \mathrm{m}$ (impulse waveform is $65 \mathrm{~ns} / 600 \mathrm{~ns}$ ) and nano$\mathrm{Al}(\mathrm{OH})_{3}$ loading with average diameter of $50 \mathrm{~nm}$ (inset figure, impulse waveform is $40 \mathrm{~ns} / 300 \mathrm{~ns}$ ). (b) Flashover performance of NMMC (impulse waveform is $40 \mathrm{~ns} / 2.5 \mu \mathrm{s}$ ). All data from [52]. All samples with the same size of diameter $60 \mathrm{~mm}$ and thickness $1 \mathrm{~mm}$. Both nanofillers and microfillers were treated by silane coupling KH550. addition of nanoparticles introduces deep level traps [13], which can restrain flashover to occur. Comparing Figure $3 a$ with Figure $3 b$, it is apparent that the surface flashover properties of NMMC are the best. The lowest flashover voltage of NMMC is observed at about $10 \%$ of microparticle content which is less than that of microcomposite.

In summary, the research on the surface flashover performance and mechanism of nano-dielectric in vacuum under a wide time-scale range of applied voltage are insufficient. The influence of nano-particle and matrix on the characteristics of nano-dielectric in vacuum has not received enough attention and more effort should been made in future. It is still unclear that which factors affect the "interaction zone" and how. The reproducibility of surface flashover performance of nano-dielectric in vacuum is poor and the comparability of the results is not good due to various possible processes.

\subsection{BREAKDOWN PROPERTIES OF NANODIELECTRICS}

BD strength of dielectric is an extremely important electrical parameter for dielectric material in engineering. Lots of research works on nanodielectric BD properties under ac or de voltage have been done so far [15-16, 53-61]. Many useful experimental data are obtained. It's unfortunate that the $\mathrm{BD}$ mechanism of nanodielectric is less clear until now.

In order to conveniently comment on the $\mathrm{BD}$ properties of nanocomposite, a ratio $k_{2}$ is defined as the previous section. Ratio $k_{2}$ versus nano-fillers loading under ac voltage is shown in Figure 4. When nanoparticles content lies in between $0.05 \mathrm{wt} \%$ and $2 \mathrm{wt} \%$, it is conducive to the ac BD strength improvement. It has been claimed [53] that ac $\mathrm{BD}$ voltage of nano- $\mathrm{Ag}$ / epoxy resin composites is $40 \%$ higher than that of the base epoxy resin when nano $\mathrm{Ag}$ particle content is about $0.05 \mathrm{wt} \%$. The authors suggested that nano Ag particles as "Coulomb Island" in epoxy resin matrix can cause "Coulomb Blockade Effects", which is useful to improve ac BD strength. However, when nanoparticles content is over a certain point (about $2 \mathrm{wt} \%$ from Figure 5), ratio $k_{2}$ decreases with nanoparticles content increasing, meaning that nano-filler has a negative effect on ac BD properties. It appears that there is an optimal value of nanoparticle content for ac BD strength. Below this value, the quantum confinement effect of nanoparticles possibly dominates the ac BD properties, or the interface plays a key role. An interesting result is that the ac BD property of NMMC is superior to nanocomposite and microcomposite [15], which is the same as the surface flashover performance. It was assumed that an increase in the possibility of an electron scattered in NMMC prevents electrical treeing from propagating efficiently. A model had been put forward for the improvement of ac BD strength in NMMC [15]. 


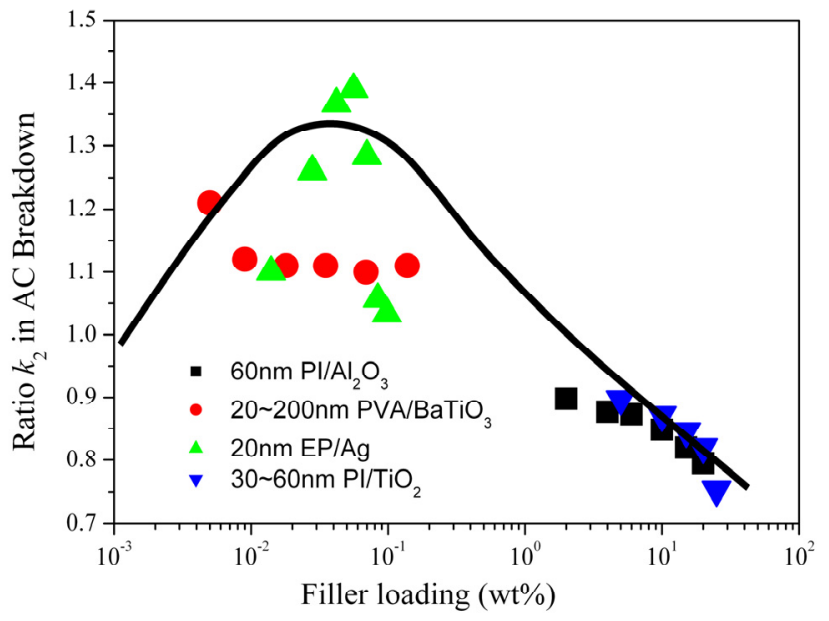

Figure 4 The relation between ratio $k_{2}$ in ac $\mathrm{BD}$ and filler loading, ( $A$ from [53], BD measurements were performed at room temperature (RT) in transformer oil according to the IEC standard. Thickness of samples is about $50 \mu \mathrm{m}$. from [54], BD measurements were performed at RT in silicon oil. Thickness of samples is $30 \pm 2 \mu \mathrm{m}$. The voltage was increased by $1 \mathrm{kV} / \mathrm{s}$. from [55], BD measurements were performed at $77 \mathrm{~K}$ in an open liquid nitrogen bath. Thickness of samples is about $50 \mu \mathrm{m}$. The voltage was increased by $500 \mathrm{~V} / \mathrm{s}$. $\boldsymbol{\nabla}$ from [56], BD measurements were performed at RT in transformer oil according to the IEC standard. Thickness of samples is $40-49 \mu \mathrm{m}$. The voltage was increased by 2.5 $\mathrm{kV} / \mathrm{s}$ ). Nanofillers in these papers were all untreated.

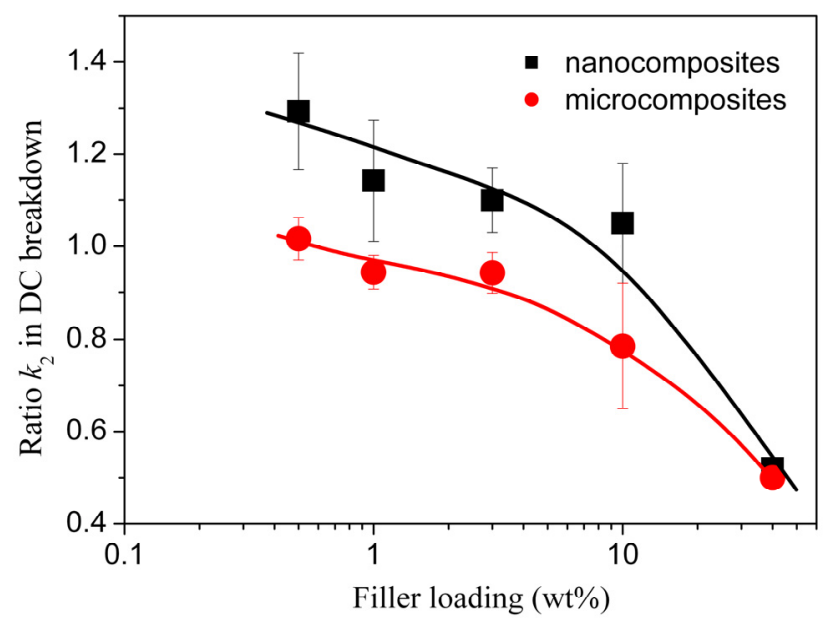

Figure 5 Ratio $k_{2}$ in dc BD versus nano/micro-filler loading, ( $\square$ from [ 57-62 ], all nanofillers in these papers were treated; $\bigcirc$ from [ 57-61 ]. ) [57] dc BD tests were performed with a ramp rate of $500 \mathrm{~V} / \mathrm{s}$. The thickness of specimens was ranging from 50 to $500 \mu \mathrm{m}$. [58] dc BD test using Mckeown type electrode was performed in silicone oil at $303 \mathrm{~K}$ with a ramp rate of $500 \mathrm{~V} / \mathrm{s}$. The thickness of sample was about $0.1 \mathrm{~mm}$. The breakdown test using needle-plane was also carried out in silicone oil at $303 \mathrm{~K}$ with a ramp rate of $200 \mathrm{~V} / \mathrm{s}$ and the thickness of samples was about $0.03 \mathrm{~mm}$. [59] dc BD measurements were performed as the same as reference [58]. [60] dc BD tests were conducted with a ramp rate of 500 $\mathrm{V} / \mathrm{s}$ and the thickness of sample was about $500-750 \mu \mathrm{m}$. [61] dc BD tests were measured at room temperature with a ramp rate of $1 \mathrm{kV} / \mathrm{s}$. The thickness was about $200 \mu \mathrm{m}$. [62] dc strength measurements were carried out in mineral oil at $20{ }^{\circ} \mathrm{C}$ with a ramp rate of $5 \mathrm{kV} / \mathrm{s}$. The thickness of specimens was about $400 \mu \mathrm{m}$. Nanofillers in these papers were all treated except [61] was unclear.

Under dc applied voltage [57 - 61], the electric strength data is compiled and illustrated in Figure 5. With filler increasing, dc BD strength decreases for both nanocomposite and microcomposite. Apparently, nanocomposite is superior to microcomposite in dc BD. Below a certain content (maybe $10 \mathrm{wt} \%$ from Figure 5), nanofillers indicates a positive effect on improving dc BD strength [57-62]. However, the dc BD strength is inferior to matrix for microfiller composite [57-61]. Microfillers presents a negative effect for dc BD. BD properties of nanodielectric under impulse voltage have been paid little attention and only a few literatures are available [57].

BD property of dielectrics depends on not only filler content, but also the applied voltage types. In the process of data compilation, an attractive phenomenon that needs to be pointed out is that the BD field stress presents a strong dependence on the applied voltage as shown in Figure 6. From Figure 6, it implies that nano-filler is beneficial to improve the BD strength of unidirectional voltage, which was affected by space charge [61].

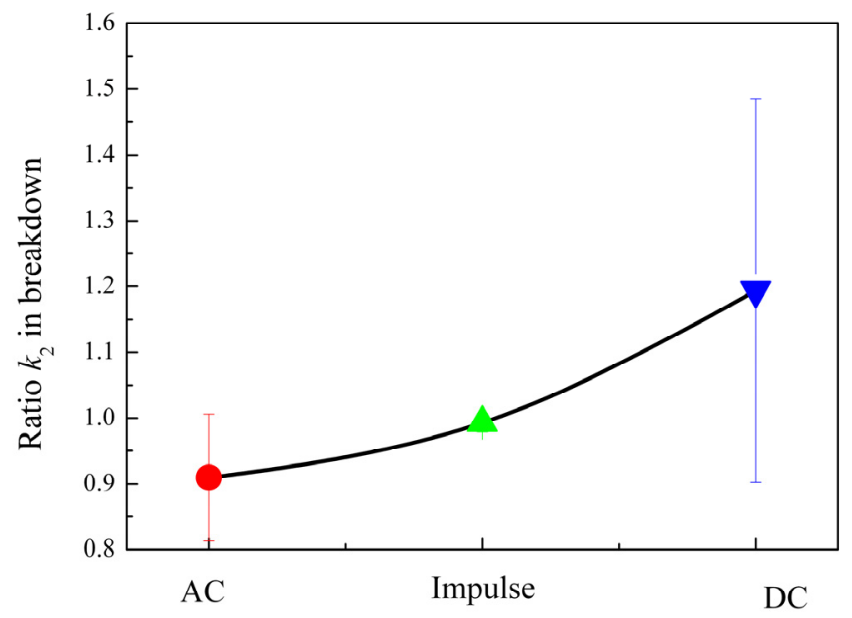

Figure 6. Ratio $k_{2}$ of nanocomposites in $\mathrm{BD}$ depend on the applied voltage type, ( $\bullet$ from [53- 57], [57] ac BD tests were measured with a ramp rate of $500 \mathrm{~V} / \mathrm{s}$. The thickness of specimens was ranging from 50 to $500 \mu \mathrm{m} ; \Delta$ from [57], impusle elecctric strength was measured using a standard impulse of $1 / 50 \mu$ s. The thickness of specimens was ranging from 50 to $500 \mu \mathrm{m} ; \boldsymbol{\nabla}$ from [57-62]).

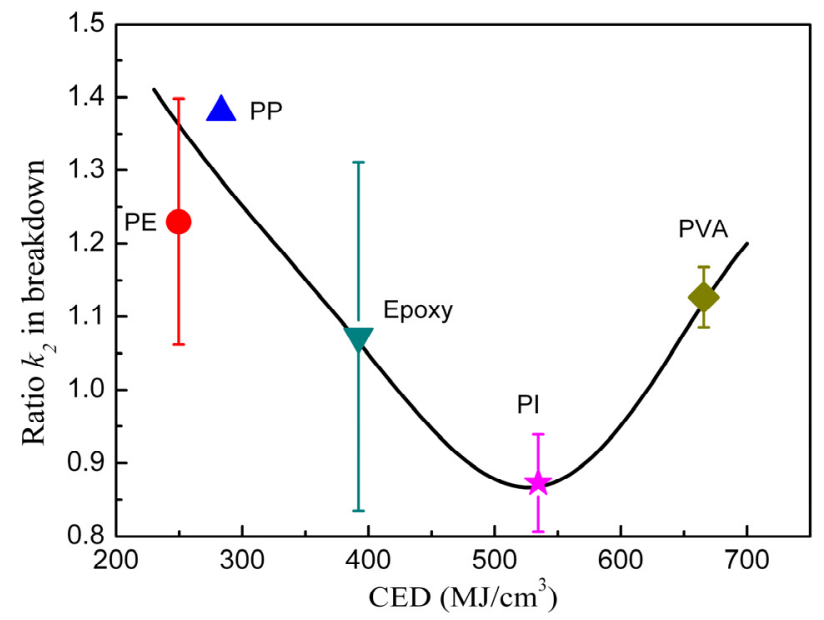

Figure 7. The relation between BD properties and CED of matrix, ( from $[58,59,61], \boldsymbol{\Delta}$ from [62], $\boldsymbol{\nabla}$ from $[53,57,60], \star$ from $[54,56]$, from [55]). 
Many polymers have been used as matrix for nanocomposites, including epoxy resin (EP), polyethylene (PE), polypropylene (PP), polyimide (PI), polyvinyl alcohol (PVA), and polyamide (PA). The physical properties of these polymers vary considerably. For an example, the cohesive energy density (CED) of PE is about $250 \mathrm{MJ} / \mathrm{m}^{3}$, while it is about $670 \mathrm{MJ} / \mathrm{m}^{3}$ for PVA. The CED of polymer can characterize the intermolecular force between polymer molecules, but also characterize the flexibility of molecular chains. It was evident that pure polymeric materials having a high CED yielded high electric strengths [60]. For nanodielectrics, by collating the existing data, it shows that the CED of polymer matrix also strongly affects the BD properties of nanocomposites. The ratio $k_{2}$ firstly decreases and then increases with the CED as shown in Figure 7. Apparently, the CED dependence of electric strength of pure polymers is different from that of polymeric nanodielectrics. It is reasonably thought that it is caused by the existence of the interfacial region between polymeric matrix and nano-particles [13]. Thus it can speculate that the CED of polymeric matrix influence the interfacial bonding strength between polymer matrix and nanoparticles. It should be mentioned that some further works are required to confirm the connection.

In addition, the permittivity of polymer matrix also has a great influence on the ratio $k_{2}$ as shown in Figure 8. The result illustrates a similarity to the CED, it decreases initially, then increases with the permittivity. Thus, it could be concluded that the CED and the dielectric constant of matrix cooperatively dominate the short-term properties of nanocomposite.

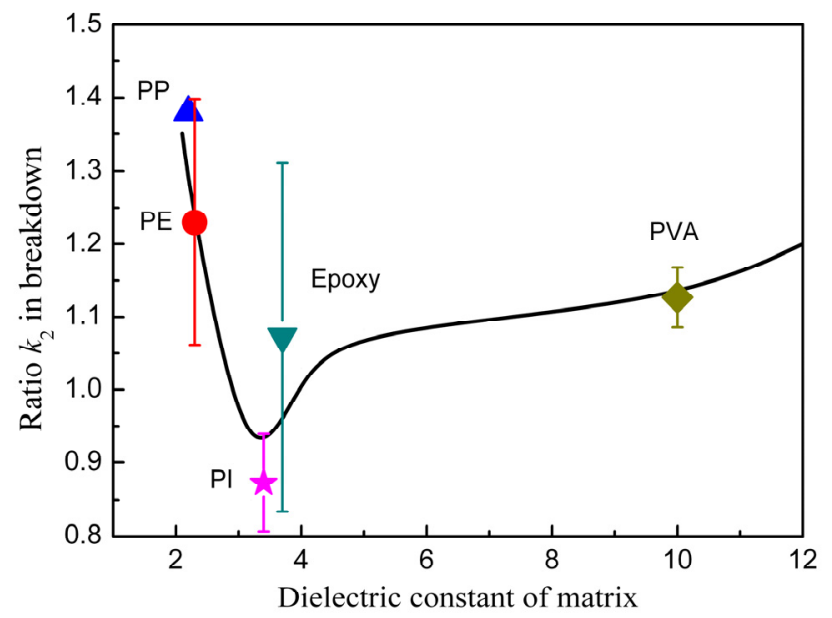

Figure 8. The influence of matrix dielectric constant on ratio $k_{2}$ in $\mathrm{BD}$, ( - from [58, 59, 61], $\boldsymbol{\Delta}$ from [62], $\boldsymbol{\nabla}$ from [53, 57, 60], $\star$ from [54, 56], $\diamond$ from [55]).

As mentioned above, the $\mathrm{BD}$ mechanism of nanodielectric is still less clear. Models on BD of nanodielectric chiefly consist of the following three: (1) Coulomb Blockade Effects (CBE) [53]. This model considers that nanoparticles scatter uniformly in polymer as "Coulomb Island", which can raise electric strength of material. It is contrary to the conventional percolation theory. (2) Space charge model [54]. Homopolar/ heteropolarity charges are accumulated to reduce / increase the electric field at the electrodes. (3) Multi-core model [13]. This model suggests that electrons lose the energy they gain from the applied voltage because they are scattered or attracted by the Coulombic force when electrons move inside the Debye shielding length. In this case, electrons are decelerated to increase breakdown voltage. Each model can explain some experimental results. The CBE model seems more suitable for nano metal particle - polymer matrix nanocomposite. The multi-core model is better to apply in nano oxide - polymer matrix composite and it's more popular than the space charge model. It is commonly thought in both the CBE model and the multicore model that the carrier mobility is restrained effectively by nano particles doping. Although several models have been proposed to illustrate the BD mechanism of nanocomposites, it's still not enough.

\section{THE PROPERTIES OF LONG-TERM FAILURE IN NANODIELECTRICS 4.1 ELECTRICAL AGEING OF NANO-
DIELECTRICS}

As mentioned in section two, the presence of "nano-hole" and LDAs caused by the molecular chain rearrangement or bond breaking will shorten the material life. Therefore, improving the ageing resistance of dielectric material can effectively extend the material life. For the same aim, we define ratio $k_{3}$ as electrical ageing performance of nanocomposite divided by that of matrix. A great deal of experimental data supported that [63-71], adding micro and nano particles could effectively improve the ageing resistance and with the ageing time prolonging, nano-composite is superior to micro-composite as shown in Figure 9. The same trends are observed in Figure 10 and Figure 11, with the filler loading increasing, the ratio $k_{3}$ monotonically increasing in the EP matrix and the PI matrix.

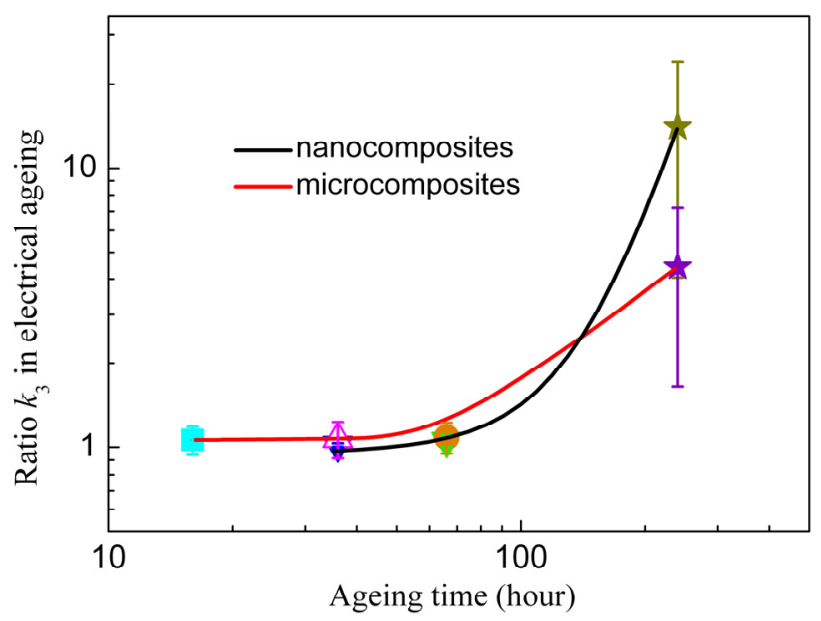

Figure 9. Electrical ageing performance of nano and micro composites at different ageing time ( $\square$ from [63], $\triangle$ from [63], $\nabla$ from [63], $\nabla$ from [64], $\bigcirc$ from [64], $\star$ from [65], $\star$ from [65] ). Nanofillers were treated in $[63,64]$ while untreated in [65]. 


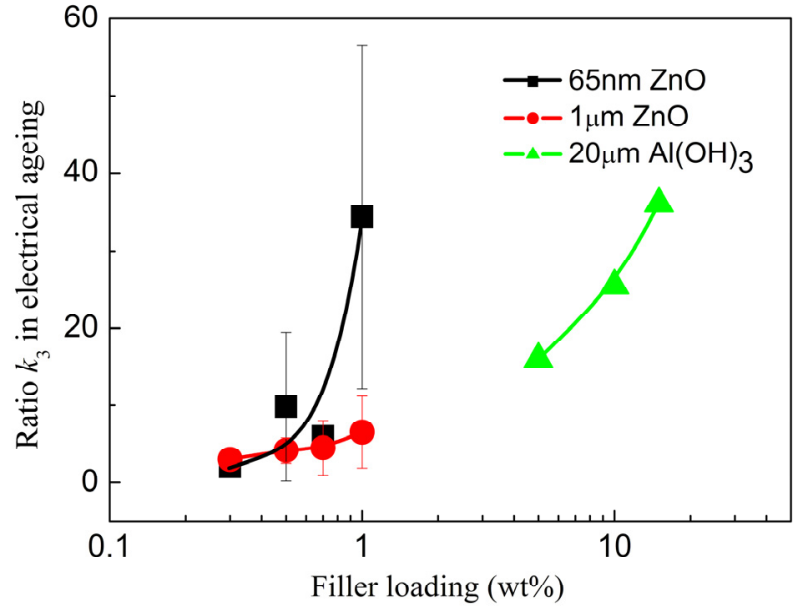

Figure 10. Electrical ageing performance of EP based resin composite, ( from [65], $\bigcirc$ from [65], $\triangle$ from [68] filler was untreated).

The matrix polarity of nanocomposite plays an important role in electrical ageing performance. With the increase of matrix polarity, the ratio $k_{3}$ increases, as shown in Figure 12. As the 2rd section described, nanohole appears in material under eletrical field due to the break of chemical bond. Since the bigger the matrix polarity, the higher the bonding strength, which leads to a better electrical ageing performance. The matrix in this review is limited to PE, PI and EP, therefore, the influence of matrix polarity on electrical ageing performance remains to be further confirmed.



Figure 11. Electrical ageing performance of $\mathrm{PI} / \mathrm{Al}_{2} \mathrm{O}_{3}$ nanocomposites under pulse voltage and dc voltage, ( $\bullet$ from [71], $\square$ from [66],); nanofillers were treated in the two papers.

\subsection{PROPERTIES IN PD RESISTANCE OF NANODIELECTRICS}

In this section, materials used as matrix mainly includes epoxy, polyolefin (such as PE, PP) and synthetic rubber (such as silicone rubber, $\mathrm{PA}$ and $\mathrm{PI}$ ). $\mathrm{Al}_{2} \mathrm{O}_{3}, \mathrm{MgO}, \mathrm{TiO}_{2}$, $\mathrm{SiO}_{2}, \mathrm{SiC}$, clay and layered silicate are chosen to be fillers [72]. Researchers have tested the PD resistance [73-82], PD breakdown [73-82] and PD lifetime [64, 82]. Ratio $k_{4}$ is the ratio of nanodielectrics to matrix in PD resistance performance. It is noticed that PD resistance has been improved in nanocomposites. Moreover, the longer the field stress applies, the better the PD resistance is observed (Figure 13). Figure 14 shows that PD resistance improves as the size of fillers decreases. The probability of electron collision with filler particles increases leading electron transport along the electric field in matrix becomes harder.

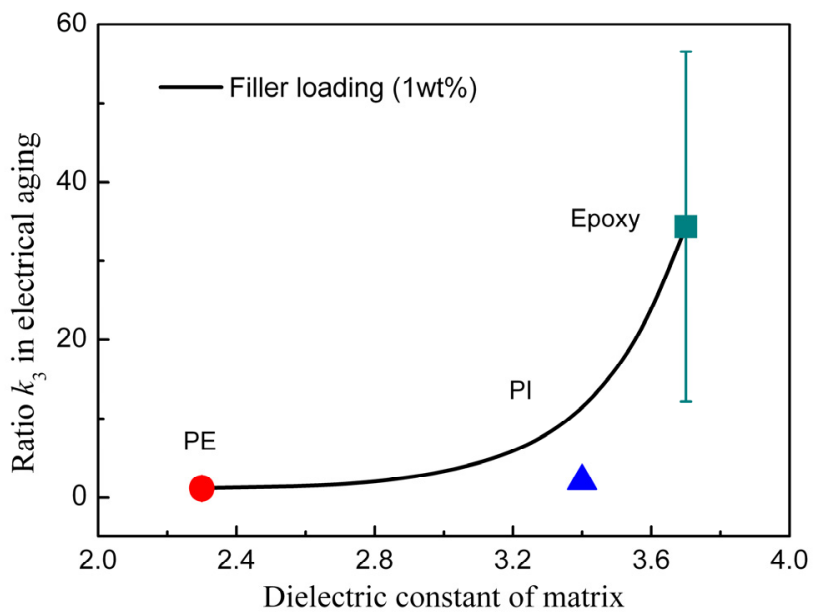

Figure 12. Long-term electrical ageing resistance in composite, Electrical ageing performance versus the dielectric constant of matrix, ( $\bigcirc$ from [67, 69], $\boldsymbol{\Delta}$ from [71], $\boldsymbol{\square}$ from [65, 68]). Nanofillers were treated in [67, $69,71]$ while untreated in $[65,68]$.

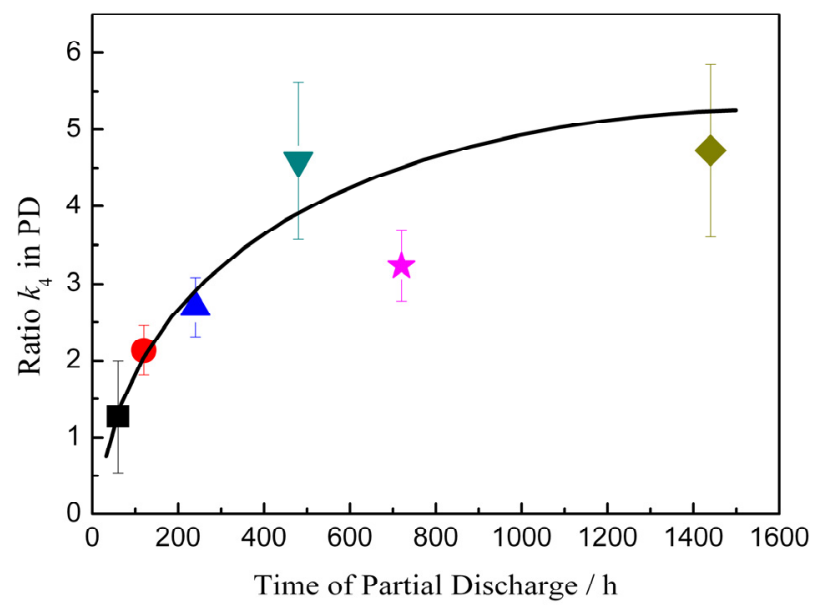

Figure 13. Ratio $k_{4}$ vs. time of PD discharge ( $\boldsymbol{\square}$ from $[15,78]$, $\bullet$ from $[15,76,77,79], \boldsymbol{\Delta}$ from $[15,75,77], \boldsymbol{\nabla}$ from [77], $\star$ from $[15,75]$, from [75] ). Nanoparticles were treated in references [15, 78, 79], others were untreated. The sizes of samples in $[75,77,78,79]$ are $50 \mathrm{~mm}$ (length) $\times 50 \mathrm{~mm}$ (width) $\times 1 \mathrm{~mm}$ (thickness), $30 \mathrm{~mm} \times 30 \mathrm{~mm} \times 1 \mathrm{~mm}, 1 \mathrm{~mm}$ (thickness, slab), $50 \mathrm{~mm}$ (width) $\times 1 \mathrm{~mm}$ (thinckness, slab), respectively.

Unlike the properties of electrical strength, CED of matrix has a positive effect on PD resistance of nanocomposites, as shown in Figure 15. With the CED increasing, PD resistance improves. Furthermore, the permittivity of the matrix is another important factor here. The PD resistance becomes better when the matrix has a higher permittivity as shown in Figure 16. 


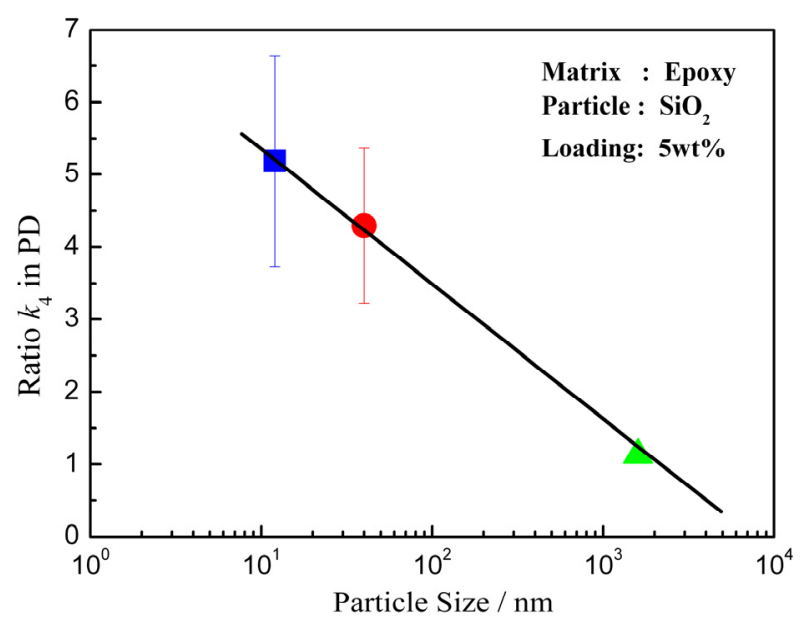

Figure 14. Ratio $k_{4}$ vs size of fillers, all data from [75].

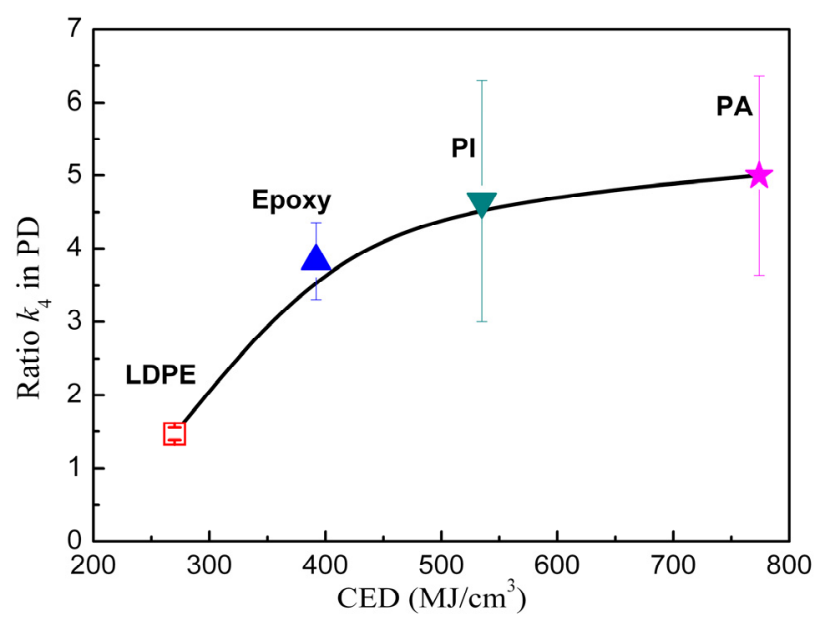

Figure 15. Ratio $k_{4}$ vs. the CED of matrix, ( $\square$ from [78], $\boldsymbol{\Delta}$ from $[15,75,77,79], \nabla$ from $[70,81], \star$ from $[73,74,80])$. Samples with the size of $60 \mathrm{~mm} \times 60 \mathrm{~mm} \times 1 \mathrm{~mm}$ were prepared by in-situ polymerization in [80], unclear in [81].

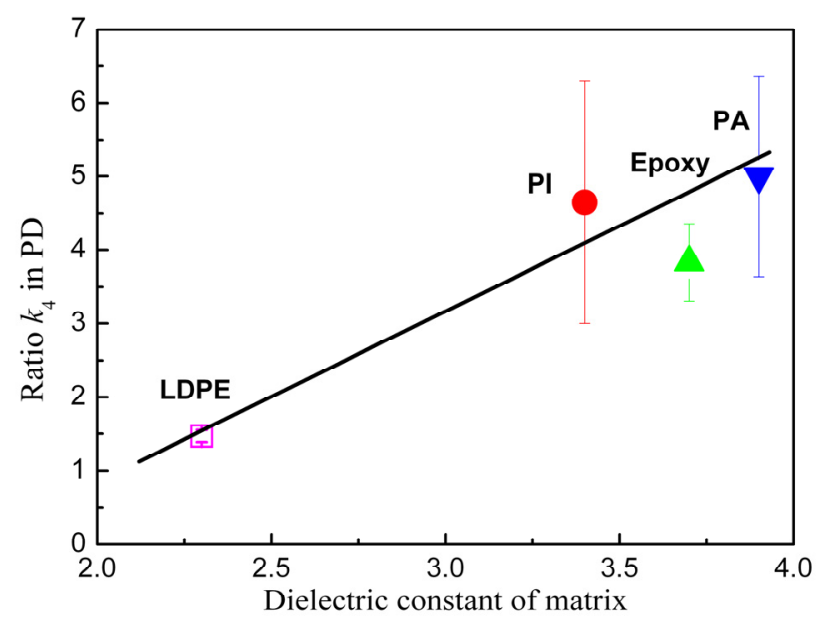

Figure 16. Ratio $k_{4}$ vs. the permittivity of matrix, ( $\square$ from [78], $\bigcirc$ from $[70,81], \Delta$ from $[15,75,77,79], \nabla$ from $[73,74,80])$.

There are several possible mechanisms to explain the improvement on the PD resistance of nanocomposites, such as the Multi-core Model [13, 83], the Skeleton Model (fillers like skeleton dividing matrix into small parts), the Size Effect of Nanoparticles [48], Pile and Rearrangement of Fillers at Surface [77, 82], Aggregative State of Space Charge [12, 8486], the Effect of the Field Homogenization and High Thermal Conductivity and Insulation Effect of Fillers [87]. However, the characteristic and function of the region between matrix and fillers are still hard to describe precisely. In addition, the distribution and the effect of space charge are not clear. More works are needed for further research.

\section{DISCUSSION}

From the above remarks, it can summarize that the short-term breakdown and the long-term failure properties are dominated by the characteristics of nanoparticles (such as polarity, size, surface states) and polymer matrix (dielectric constant and CED for instance). In the view of the interface influenced at nanolevel by the two materials, the permittivity of particles, the polarity and the CED of polymer affect the shortterm breakdown properties of composites. The latter two, respectively, influence the electric ageing properties and the PD properties. Since the interface is the bridge to connect the particles with the matrix, its construction and properties are determined by both. A "Multi-Core" model has been proposed by T. Tanaka to describe the microstructures and properties of interfaces in nanocomposite [13]. It has been successfully used to explain a lot of experimental results and is generally accepted in the nanodielectric research field. However, some experimental phenomena can not be explained well. Such as, the crystallinities of both microcomposites and untreated nanocomposites were quantitatively the same as that of the pure XLPE, whereas the vinylsilane-treated nanocomposite had about $33 \%$ higher crystallinity than the other composites [12]. A large number of heterocharges developed near the electrodes in the untreated-silica/LLDPE nanodieletrics, while a very small number of homocharges in the treatedsilica/LLDPE nanodielectrics. The treated silica agglomerates showed nucleating effect and reduced the size and perfection of the spherulites, and the measurement of water contact angle also indicated great difference between the treated and untreated silica nanocomposites [88]. The breakdown strength of treated$\mathrm{TiO}_{2} / \mathrm{LDPE}$ showed a nearly $40 \%$ increase than that of as-received nanoscale $\mathrm{TiO}_{2}$-filled specimens [89]. These results mean that the surface condition of nanoparticles is the dominant factor to determine the macroscopic performances of nanodielectrics. The surface condition of particles affects the interaction between the nanofillers and polymer matrix. Therefore, it is reasonably deduced that the interfacial structure of treated nanodielectrics is different from that of untreated ones. Considering both treated and untreated, we propose a schematic of multi- 
region structure around spherical nanoparticles as shown in Figure 17:

(1) Bonded region: Due to abundant unsaturated bonds, hydrogen and organic groups (silane couplings) existing on the surface of nanoparticles, fillers can easily connect with the polymer matrix by covalent, ionic and hydrogen bonds. The van der Waals force is another type of interaction between filler and matrix. Moreover, the polarity of particles and matrix has a non-ignorable influence on the bonding strength. The bigger the permittivity, the stronger the force between the two kinds of material. It is important to state which kind of force is primary in the bonded region in actual cases. Bonding strength is the strongest at the interface.

According to the colloid chemistry, a Stern layer is formed due to a portion of counter ions adsorbed around nanoparticles by electrostatic Coulomb force and other forces since the Fermi level is different between inorganic particles and polymer matrix. It is speculated that a vast distortion of potential occurs in bonding region and deep traps with the highest density are introduced. Outwards from the surface of nanoparticles, the density of traps decrease and the shallow traps gradually take a dominated position. Plenty of space charges are accumulated under the applied field so that electric field increases sharply which leads to the breakdown firstly occurring in a bonded region. In general, the bonded region has a key role in short-term breakdown properties of nanocomposites.

(2) Transitional region: Molecular chain of polymer matrix consists of the transitional region and strongly bound with the bonded region and nanoparticles surface. Molecular chain arranges orderly in this region leading each chain endured an average force under electromechanical stress. The characteristic of the region is influenced chiefly by the CED of matrix. The larger the CED, the better the flexibility of molecular chain. So, more energy is needed to break the chain up. In this way, the service life of material will be extended effectively.

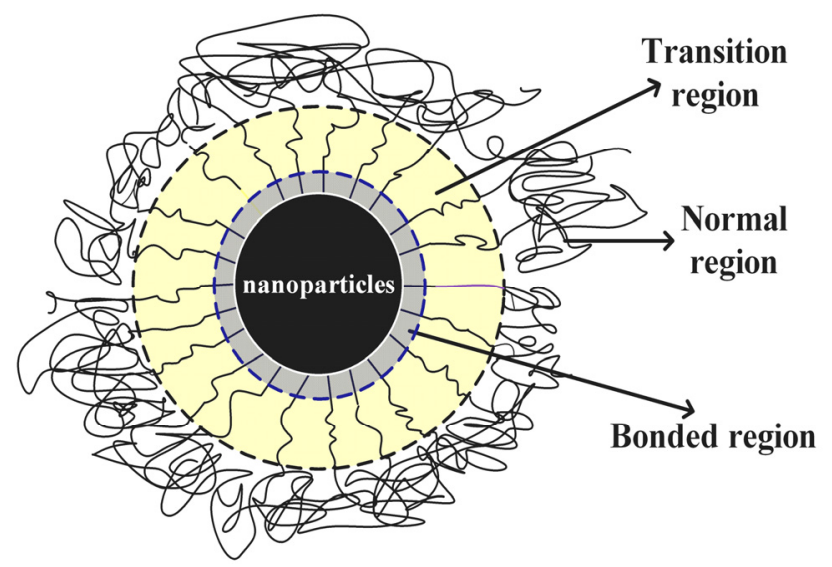

Figure 17. Schematic of multi-region structure around spherical 1oparticles.

The chain mobility of molecular chain and crystallinity are involved in nanocomposites. The former determines directly the glass transition temperature. The latter is higher than the matrix originated from crystalline structure formed due to the existence of nanoparticles. The transitional region is considered as the crystalline structure region.

Bonded region and transitional region collaboratively determine the long-term degradation properties of composites. The thickness of the transitional region is greater than bonded region and affected by the surface condition of nano-fillers.

(3) Normal region: the properties of normal region are similar to the matrix. The molecular chains wind around the nanoparticles randomly.

Based on the knowledge of the three regions, assuming nanoparticles in an ideal dispersion, with fillers content increasing, the short-term and long-term properties are indicated as follows:

1) The long-term failure properties of nanodielectrics are independent of the nanoparticles content at an extremely low content due to the volume of the bonded region and the transition region at a low level. However, the short-term breakdown strength indicates a high improvement. At this case, slight nano-dopant can strikingly raise the BD strength, but of no use for the long-term properties.

2) As the nanoparticle content increases, the volume of the bonded region and the transition region increases. This will alter the glass transition temperature and melting temperature of polymeric matrix. The latter has been observed [90] in linear low density polyethylene filled with different level of alumina nanoparticles.

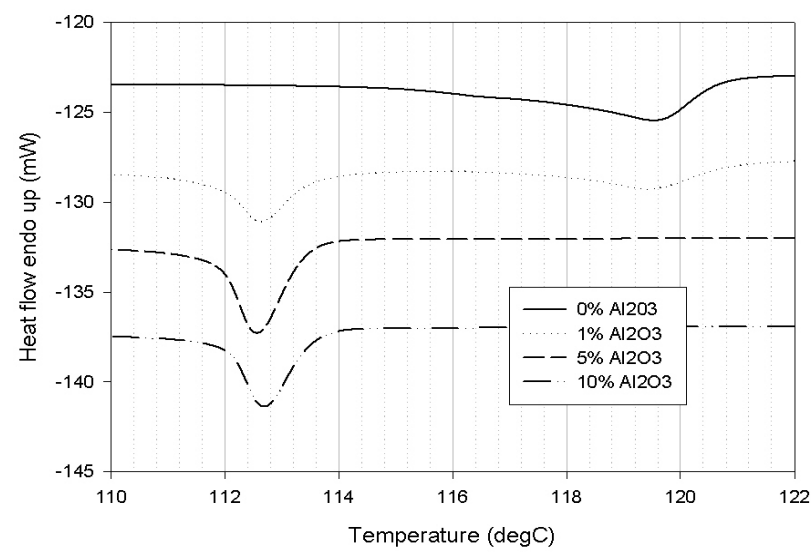

Figure 18. DSC curves for nano alumina filled LLDPE samples [90].

Analysis of the melting behavior of various nano alumina content added into linear low density polyethylene (LLDPE) was carried out using differential scanning calorimetry (DSC). The samples were placed in an aluminum can heated to $200{ }^{\circ} \mathrm{C}$ and were cooled at $1{ }^{\circ} \mathrm{C} / \mathrm{min}$ to room temperature. The DSC results were shown in Figure 18. The information obtained from Figure 18 is that there are two processes, one at just below $120{ }^{\circ} \mathrm{C}$ which was observed in the pure LLDPE and sample filled with $1 \%$ nano alumina particles and the other at just above $112{ }^{\circ} \mathrm{C}$ 
which appears in all the filled samples. An attractive phenomena should be pointed out is that only the sample with $1 \%$ filled displays both of these characteristics. This may be seen as a direct evidence for a region called transition region around the nanoparticles where the LLDPE behaves completely differently than the pure sample. This region then composes of the samples with the nanoparticles content increasing, such as 5\% and 10\% filled. Therefore, it is presumed that the long-term properties have a significantly improvement with filler content increasing. The short term breakdown strength is reduced due to the volume of bonded region increasing.

3) Nanoparticle overlaps with its neighbor particles when nanoparticles content is over percolation threshold. The short-term properties and the long-term properties may be stable and the performance of nanoparticles gradually takes a leading role in determining nanodielectrics properties.

Thus, the mechanism of the short-term breakdown and the long-term failure may be schematically represented in Figure 19.

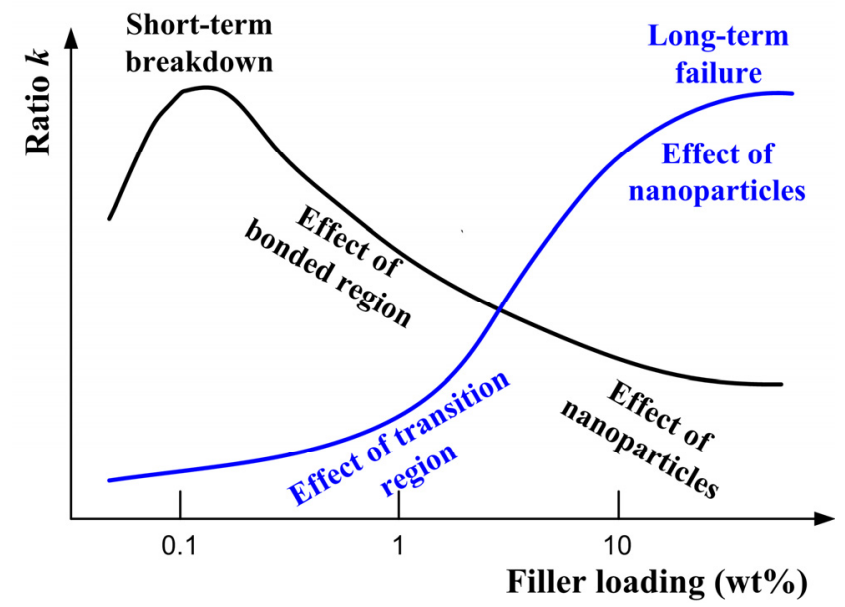

Figure 19. The schematic diagram of the short-term breakdown and the long-term failure.

\section{SUMMARY AND SUGGESTIONS FOR FURTHER WORK}

Dielectric material perfromance, whether conventional or nanocomposite dielectric, its aging, degradation and breakdown present a strong spatio-temporal hierarchy relationship. The $\mathrm{BD}$ mechanism is Fowler-Nordheim tunnel breakdown, for conventional dielectric, when the distance between electrodes is near to a nanometer. From aging, to the degradation, to the evolution of breakdown process, the aging process occurs on the nano-level, while the degradation occurs from the nanometer to the micron level. The research on the multi-hierarchical structure and the macroscopic properties of nanodielectric should not be limited to the nanocomposite dielectric, and should be extended to the conventional dielectric since aging, degradation and breakdown occurred from nanometers to microns and then to $\mathrm{mm}$, multi-levels are observed in conventional dielectric material. Therefore, it is necessary to research the mechanism of aging and degradation of dielectric material on the nano-level, and improve the operating reliability of dielectric materials in a variety of working conditions.

Since the interface is affected by both matrix properties and nano-particle properties on nano-level, the following two interesting aspects of nanocomposites are summarized. On the one hand, the permittivity of nano-particle affects the vacuum surface flashover performance of the nanocomposite. The higher the particle dielectric constant, the higher the vacuum surface flashover voltage. On the other hand, the CED and the dielectric constant of matrix are closely-related with the composite electrical breakdown. When increasing matrix dielectric constant, the electrical breakdown field of the composite decreases initially and then increases, the electrical ageing performance improves all the time. Although the above two conclusions are common, further validation is still needed. In order to understand the impact of filler and matrix on short-term breakdown and long-term failure, it is also necessary to investigate the dependence of the nano-level structure of composite on permittivity of fillers, matrix dielectric constant and CED.

It can also come to the conclusion that the aggregative state of nano-particle contributes significantly to the shortterm breakdown and long-term failure. The studies have indicated that as the amount of nano-particle increases, the short-term breakdown properties worsens, they can only improve with a small filler loading, while the long-term failure performance improve with filler amount increasing. Therefore, different characteristics are shown for the dependency of the amount of nanoparticles on the shortterm breakdown and long-term failure properties.

From this point of view, making further efforts on the aggregative state of nano-particle, understanding the coupling effect of interface and their impact on short-term breakdown and long-term failure are meaningful. These studies may reveal the regulation and mechanism at spatialtemporal hierarchical about the short-term breakdown and long-term failure of nanocomposite.

\section{ACKNOWLEDGMENT}

This work is supported by the National Science Foundation for Distinguished Young Scholars of China (Grant No. 50625721), New-Century Talents Program of Ministry of Education (Grant No. NCET-05-0833) and Project by State Key Laboratory of Electrical Insulation and Power Equipment (Grant No. EIPE09106) and the National Basic Research Program of China (Grant No. 2009CB724505). 


\section{REFERENCES}

[1] K. S. Zhao and K. J. He, "Dielectric relaxation of suspensions of nanoscale particles surrounded by a thick electric double layer", Phys. Rev. B., Vol. 74, pp. 205319-1-205319-10, 2006.

[2] P. Kim, N. M. Doss, J. P. Tillotson, P. J. Hotchkiss, M. J. Pan, S. R. Marder, J. Y. Li, J. P. Calame and J. W. Perrty, "High energy density nanocomposites based on surface-modified $\mathrm{BaTiO}_{3}$ and a ferroelectric polymer", American Chem. Soc. Nano, Vol. 3, pp. 2581-2592, 2009.

[3] L. Chen and G. H. Chen, "Relaxation behavior study of silicone rubber crosslinked network under static and dynamic compression by electric response", Polymer Composite, Vol. 30, pp. 101-106, 2009.

[4] H. Tan and W. Yang, "Toughening mechanisms of nano-composite ceramics", Mechanics of Materials, Vol. 30, pp. 111-123, 1998.

[5] H. Awaji, Y. Nishimura, S. M. Choi, Y. Takahashi, T. Goto and S. Hashimoto, "Toughening mechanism and frontal process zone size of ceramics", J. Ceramic Soc. of Japan, Vol. 117, pp. 623-629, 2009.

[6] G. X. Zeng, H. Y. Zhang, L. C. Hu and Y. M. Chen, "Research on complex permittivity spectrum and microwave absorption of anti-infrared $\mathrm{In}(\mathrm{Sn})_{2} \mathrm{O}_{3}$ (ITO) painting", J. Aeronautical Materials, Vol. 28, pp. 87-90, 2008.

[7] C. Zhang, "Stealthy nanomaterials and its applications in the informative war", Micronanoelectronic Technology, Vol. 42, pp. 495-499, 2005.

[8] D. R. Sahu and B. K. Roul, "Investigation of CMR properties in perovskite manganites", American Inst. Phys. Conf. Proc. Mesoscopic, Nanoscopic, and Macroscopic Materials, pp. 190-205, 2008.

[9] K. H. Song, B. J. Park and H. J. Choi, "Effect of magnetic nanoparticle additive on characteristics of magnetorheological fluid", IEEE Trans. Magnetics, Vol. 45, pp. 4045-4048, 2009.

[10] T. Imai, Y. Hirano, H. Hirai, S. Kojima and T. Shimizu, "Preparation and properties of epoxy-organically modified layered silicate nanocomposites", IEEE Intern. Sympos. Electr. Insul. (ISEI), Boston, USA, pp. 379-383, 2002.

[11] J. K. Nelson, J. C. Fothergill, L. A. Dissado and W. Peasgood, "Toward an understanding of nanometric dielectrics", IEEE-CEIDP, pp. 295-298, 2002.

[12] M. Roy, J. K. Nelson, R. K. MacCrone, L. S. Schadler, C. W. Reed, R. Keefe and W. Zenger, "Polymer nanocomposite dielectrics - the role of the interface", IEEE, Trans. Dielectr. Electr. Insul, Vol. 12, pp. 629-643 and p.1273 (Erratum), 2005.

[13] T. Tanaka. "Dielectric Nanocomposites with Insulating Properties", IEEE Trans. Dielectr. Electrical Insul., Vol. 12, pp. 914-928, 2005.

[14] G. L. Wilkes and J. Y. Wen, "Organic/Inorganic hybrid network materials by the Sol-Gel approach", Chem. Mater, Vol. 8, pp. 1667-1681, 1996.

[15] T. Imai, F. Sawa, T. Nakano, T. Ozaki, T. Shimizu, S. Kuge, M. Kozako and T. Tanaka, "Insulation properties of nano- and micro- filler mixture composite", IEEE Conf. Electr. Insul. Dielectr. Phenomena (CEIDP), pp. $171-174,2005$.

[16] S. Masuda, S. Okuzumi, R. Kurniant, Y.Murakami, M. Nagao, Y. Murata, and Y. Sekiguchi, "DC conduction and electrical breakdown of $\mathrm{MgO}$ and LDPE nanocomposite", IEEE Conf. Electr. Insul. Dielectr. Phenomena (CEIDP), pp. 290-293, 2007.

[17] J. K. Nelson, Y. Hu and J. Thiticharoenpong. "Electrical properties of $\mathrm{TiO}_{2}$ nanocomposites", IEEE Conf. Electr. Insul. Dielectr. Phenomena (CEIDP), pp. 719-722, 2003

[18] J. C. Fothergill, "Ageing, space charge and nanodielectrics: ten things we don't know about dielectrics", IEEE Intern. Conf. Solid Dielectrics, Winchester, UK, pp.1-10, 2007.

[19] J. D. Chen and Z. Y. Liu, Dielectric Physics, Beijing: Machinery Industry Press, 1982. (in Chinese)

[20] Dielectric Physics, Xi'an Jiaotong University press, 1961.08. (in Chinese)

[21] J. P. Crine, "A molecular model to evaluate the impact of aging on space charge in polymer dielectrics", IEEE Trans. Dielectr. Electr. Insul., Vol. 4, pp. 487-495, 1997.

[22] Q. Q. Lei , X. Wang and L. J. He, "Review, thinking and countermeasure about engineering dielectric theory", High Voltage Engineering, Vol. 33, pp. 1-4, 2007. (in Chinese)

[23] J. C. Fothergill, G. C. Montanari, G. C. Stevens, C. Laurent, G. Teyssedre, L. A. Dissado, U. H. Nilsson and G. Platbrood, "Electrical, microstructural, physical and chemicalcharacterization of HV XLPE cable peelings for an electrical aging diagnostic data base", IEEE Trans Dielectr. Electr. Insul., Vol. 10, pp. 514-527, 2003.

[24] T. J. Lewis, J. P. Llewellyn, M. J. van der Sluijs, J. Freestone and R. N. Hampton, "A new model for electrical ageing and breakdown in dielectrics", IEE DMMA, Conf. Pub. No. 430, pp. 220-224, 1996.

[25] T. J. Lewis, "Aging - a perspective", IEEE Electr. Insul. Mag., Vol.17, No.4, pp. 6-16, 2001.

[26] T. J. Lewis, J. P. Llewellyn and M. J. van der Sluijs, "Electrokinetic properties of metal-dielectric interfaces", IEE Proceedings-A, Vol. 140, pp. 385-392., 1993.

[27] T. J. Lewis, J. P. Llewellyn and M. J. van der Sluijs, "Electrically induced mechanical strain in insulating dielectrics". IEEE Conf. Electr. Insul. Dielectr. Phenomena (CEIDP), pp. 328-333, 1994.

[28] T. J. Lewis, J. P. Llewellyn, M. J. van der Sluijs, J. Freestone and R. N. Hampton, "Electromechanical effects in XLPE cable models", IEEE $5^{\text {th }}$ Intern. Conf. Solid Dielectr. (ICSD), (Pub. 95CH3476-9), pp. 269-273, 1995.

[29] P. Connor, J. P. Jones, J. P. Jones, J. P. Llewellyn and T. J. Lewis, "Electric field-induced viscoelastic changes in insulating polymer films", IEEE Conf. Electr. Insul. Dielectr. Phenomena (CEIDP), pp. 27-30, 1998.

[30] P. W. Sayers, T. J. Lewis, J. P. Llewellyn and C. L. Griffiths, "Investigation of the structural changes in LDPE and XLPE induced by high electrical stress", IEE DMMA, Conf. Pub. No. 473, pp. 403-407, 2000.

[31] C. L. Griffiths, S. Betteridge, J. P. Llewellyn and T. J. Lewis, "The importance of mechanical properties for increasing the electrical endurance of polymeric insulation", IEE DMMA, Conf. Pub. No. 473, pp. 408-411, 2000.

[32] J. P. Jones, J. P. Llewellyn and T. J. Lewis, "The contribution of fieldinduced morphological change to the electrical aging and breakdown of polyethylene", IEEE Trans. Dielectr.Electr. Insul, Vol. 12, pp. 951-966, 2005.

[33] L. A. Dissado, G. Mazzanti and G. C. Montanari, "The incorporation of space charge degradation in the life model for electrical insulating materials", IEEE Trans. Dielectr. Electr. Insul, Vol. 2, pp. 15-25, 1995.

[34] L. A. Dissado, G. Mazzanti and G. C.Montanari, "The role of trapped space charges in the electrical aging of insulation materials", IEEE Trans. Dielectr. Electr. Insul, Vol. 4, pp. 496-506, 1997.

[35] L. A. Dissado, G. Mazzanti and G. C.Montanari, "Discussion of spacecharge life model features in dc and ac electrical aging of polymeric materials", Minneapolis, pp. 36-40, 1997.

[36] L. A. Dissado, G. Mazzanti and G. C. Montanari, "A space-charge life model for ac electrical aging of polymers", IEEE Trans. Dielectr. Electr. Insul, Vol. 6, pp. 864-875, 1999.

[37] L. A. Dissado, G. Mazzanti and G. C.Montanari, "Elemental strain and trapped space charge in thermoelectrical aging of insulating materials Part 1: Elemental strain under thermo-electrical-mechanical stress", IEEE Trans. Dielectr. Electr. Insul, Vol. 8, pp. 959-965, 2001.

[38] G. Mazzanti, G. C.Montanari and L. A. Dissado, "Elemental strain and trapped space charge in thermoelectrical aging of insulating materials life modelling", IEEE Trans. Dielectr. Electr. Insul, Vol. 8, pp. 966-971, 2001.

[39] C. Dang, J. L. Parpal and J. P. Crine, "Electrical aging of extruded dielectric cables review of existing theories and data", IEEE Trans. Dielectr. Electr. Insul, Vol. 3, pp. 237-247, 1996.

[40] J. L. Parpal, J. P. Crine and C. Dang, "Electrical ageing of extruded dielectric cables - a physical model", IEEE Trans. Dielectr. Electr. Insul, Vol.4, pp.197-209, 1997.

[41] H. C. Miller, "Flashover of insulators in vacuum: review of the phenomena and techniques to improve holdoff voltage", IEEE Trans. Electr. Insul, Vol.28, pp. 512-527, 1993.

[42] H. Kirkici, M. Serkan and K. Koppisetty, "Nano/micro dielectric surface flashover in partial vacuum", IEEE Trans. Electr. Insul, Vol.14, pp. 790795, 2007.

[43] M. Serkan, H. Kirkici and K. Koppisetty, "Surface flashover characteristics of nano-composite dielectric materials under DC and pulsed signals in partial vacuum", IEEE 27th Power Modulator Symposium, pp. 90-92, 2006.

[44] G. J. Zhang, W. B. Zhao, N. Zheng, K. K. Yu, X. P. Ma and Z. Yan, "Research process on surface flashover phenomena across solid 
insulation in vacuum", High Voltage Engineering, Vol. 33, pp. 30-35, 2007. (in Chinese)

[45] Liu Tong, "Study on Vacuum Flashover Properties of Epoxy Resin Materials under Nano-Second Pulsed Voltages" [M], Xi'an Jiaotong University, 2006. (in Chinese)

[46] Zhang Lei, "Study on new Epoxy Resin Composite Material Used in Vacuum Insulator" [M], Xi'an Jiaotong University, 2005. (in Chinese)

[47] Y. Chen, Y. H. Cheng, Z. B. Wang, K. Wu and S. T. Li, "Fast pulse flashover of micro-nano-inorganic oxide and epoxy composite in Vacuum", Advances in Natural Science, Vol.18, pp. 956-960, 2008. (in Chinese)

[48] Y. Chen, Y. H. Cheng, W. Yin, W. K. Li, G. D. Meng, Z. B. Wang, J. B. Zhou and $\mathrm{K}$. Wu, "Flashover property of pure epoxy and composites along the gas-solid interface under fast pulse", J. Xi'an Jiaotong University, Vol. 42, pp. 703-707, 2008. (in Chinese)

[49] Y. H. Cheng and Y. Chen, "Study on the vacuum surface flashover characteristics of epoxy composites with different fillers under steep high-voltage impulse", 9th IEEE International Conference on Solid Dielectrics, pp. 349-352, 2007. (Also see "Y. Chen, Y. H. Cheng, K. Wu, J. K. Nelson, L. A. Dissado and S. T. Li, "Flashover Characteristic of Epoxy Composites Filled With Different Micro-Inorganic Oxide Particles Under Nanosecond Pulse in Vacuum", IEEE Trans. Plas. Sci,Vol.37, pp. 195-203, 2009).

[50] Y. Chen, Y. H. Cheng, J. B. Zhou, Z. B. Wang, K. Wu and T. Tanaka, "Pulsed vacuum flashover of $\mathrm{Al}_{2} \mathrm{O}_{3}$ /epoxy nanocomposite", Intern. Conf. Electrical Insulating Materials, pp. 36-39, 2008.

[51] W. Zhao, G. Zhang and Y. Yang, "Correlation between trapping parameters and surface insulation strength of solid dielectric under pulse voltage in vacuum", IEEE Trans. Dielectr. Electr. Insul., Vol.14, pp.170$178,2007$.

[52] Y. Chen, "Study on Pulsed Flashover characteristic of Epoxy composites in Vacuum" [D], Xi'an Jiaotong University, 2008. (in Chinese)

[53] M. Xu, J. Q. Feng and X. L. Cao, "Study on preparation and dielectric properties of nano-Ag/epoxy resin composite", Rare Metal Materials and Engineering, Vol. 36, pp. 1369-1372, 2007.

[54] H. Y. Li, G. Liu, B. Liu, W. Chen and S. T. Chen, "Dielectric properties of polyimide $/ \mathrm{Al}_{2} \mathrm{O}_{3}$ hybrids synthesized by in-situ polymerization", Materials Letters, Vol.61, pp. 1507-1511, 2007.

[55] E. Tuncer, R. C. Duckworth, I. Sauers, D. R. James and A. R. Ellis, "Dielectric properties of polyvinyl alcohol filled with nanometer size barium titanate particles", IEEE Conf. Electr. Insul. Dielectr. Phenomena (CEIDP), pp. 225-227, 2007. (Also see "E. Tuncer, I. Sauers, D. R. James, A. R. Ellis, A. Goyal and K. L. More, "Enhancement of dielectric strength in Nanocomposites", Nanotechnology, Vol. 18, pp. 1-5, 2007.)

[56] H. Y. Li, L. Guo, B. Liu, W. Chen and S. T. Chen, " A study of dielectric properties of polyimide/nano-titanium/dioxide composites films", Insulation material, No.6, pp. 30-33, 2005. (in Chinese)

[57] Y. J. Hu, R. C. Smith, J. K. Nelson and L. S. Schadler, "Some mechanistic understanding of the impulse strength of nanocomposites", IEEE Conf. Electr. Insul. Dielectr. Phenomena (CEIDP), pp. 31-34, 2006.

[58] Y. Murakami, M. Nemoto, S. Okuzumi, S. Masuda and M. Nagao, "DC conduction and electrical breakdown of $\mathrm{MgO} / \mathrm{LDPE}$ nanocomposite", IEEE Trans. Dielectr. Electr. Insul, Vol. 15, pp. 33-39, 2008.

[59] S. Okuzumi, Y. Murakami, M. Nagao, Y. Sekiguchi, C. C. Reddy and Y. Murata, "DC breakdown strength and conduction current of MgO/LDPE composite influenced by filler size", IEEE Conf. Electr. Insul. Dielectr. Phenomena (CEIDP), pp. 722-725, 2008.

[60] J. K. Nelson and J. C. Fothergill, "Internal charge behaviour of nanocomposites", Nanotechnology, Vol.15, pp.586-595, 2004. (Also see "H. Sabuni and J. K. Nelson, "Factors determining the electric strength of polymeric dielectrics", J. Materi. Sci. Vol. 11, pp. 1574-1576, 1976”.)

[61] Y. Yin, X. B Dong, Z. Li and X. G. Li, "The effect of electrically prestressing on DC breakdown strength in the nanocomposite of lowdensity polyethylene/nano-SiOx", IEEE Intern. Conf. Solid Dielectrics, pp. 372-376, 2007.

[62] C. Zilg, D. Kaempfer, R. Thomann, R. Muelhaupt and G. C. Montanari, "Electrical properties of polymer nanocomposites based upon organophilic layered silicates", IEEE Conf. Electr. Insul. Dielectr. Phenomena (CEIDP), pp.546-550, 2003.
[63] C. M. Li, R. P. Li, J. G. Gao, Y. B. Wu and X. H. Zhang, "Influences of nano-montmorillonite on breakdown and electrical conductivity of polyethylene", J. Harbin University of Sci, Techn., Vol. 12, pp. 152-155, 2009. (in Chinese)

[64] X. H. Zhang, J. G. Gao and N. Guo, "Influences of nano-montmorillonite on breakdown and electrical conductivity of polyethylene", High Voltage Engineering, Vol. 35, pp. 129-134, 2009. (in Chinese)

[65] H. Z. Ding and B. R. Varlow, "Effect of nano-fillers on electrical treeing in epoxy resin subjected to AC voltage", IEEE Conf. Electr. Insul. Dielectr. Phenomena (CEIDP), pp. 332-335, 2004.

[66] H. Y. Li, G. Liu, B. Liu and W. Chen, "Dielectric properties of polyimide $/ \mathrm{Al}_{2} \mathrm{O}_{3}$ hybrids synthesized by in-situ polymerization", Materials Letters, Vol. 61, pp. 1501-1511, 2007.

[67] T. Tanaka, "High field light emission in LDPE/MgO nanocomposite", Intern. Sympos. Electrical Insulating Materials, pp. 506-509, 2008.

[68] H. Z. Ding and B. R. Varlow, "Filler volume fraction effects on the breakdown resistance of an epoxy microcomposite dielectric", IEEE Intern. Conf. Solid Dielectrics, Vol. 2, pp. 816-820, 2004.

[69] R. Kurnianto and Y. Murakami, "Some fundamentals on treeing breakdown in inorganic-filler/LDPE nano-composite material", IEEE Conf. Electr. Insul. Dielectr. Phenomena (CEIDP), pp. 373-376, 2006.

[70] M. Y. Zhang, C. Yan, F. Yong and Q. Q. Lei, "Synthesis and characterization of corona-resistant nanocluster-trapped polyimide/silica composites", IEEE 7th Intern. Conf. Properties and Applications of Dielectric Materials(ICPADM), Nagoya, Japan, pp. 753-756, 2003.

[71] H. Zhou, Y. Fan and Q. Q. Lei, "Synthesis and characterization of corona-resistant polyimide/alumina hybrid films", IEEE 8th Intern. Conf. Properties and Applications of Dielectric Materials (ICPADM), pp. 736738, 2006

[72] T. Tanaka, G. C. Montanari and R. Mülthaupt, "Polymer nanocomposites as dielectrics and electrical insulation perspectives for processing technologies, material characterization and future applications", IEEE Trans. Electr. Insul, Vol.11, pp. 763-784, 2004

[73] M. Kozako, R. Kido, N. Fuse, Y. Ohki, T. Okamoto and T. Tanaka, "Difference in surface degradation due to partial discharges between polyamide nanocomposites and microcomposites", IEEE Conf. Electr. Insul. Dielectr. Phenomena (CEIDP), pp. 398-401, 2004.

[74] N. Fuse, M. Kozako, T. Tanaka, S. Murase and Y. Ohki, "Possible mechanism of superior partial-discharge resistance of polyamide nanocomposites", IEEE Conf. Electr. Insul. Dielectr. Phenomena (CEIDP), pp. 322-325, 2004.

[75] M. Kozako, S. Kuge, T. Imai, T. Ozaki, T. Shimizu and T. Tanaka, "Surface erosion due to partial discharges on several kinds of epoxy nanocomposites", IEEE Conf. Electr. Insul. Dielectr. Phenomena (CEIDP), pp. 162-165, 2005.

[76] M. Kozako, Y. Ohki, M. Kohtoh, S. Okabe and T. Tanaka, "Preparation and various characteristics of epoxy/alumina nanocomposites", IEEJ Trans. FM, Vol. 126, pp. 1121-1127, 2006.

[77] T. Tanaka, Y. Matsuo and K. Uchida, "Partial discharge endurance of epoxy / SiC nanocomposite", IEEE Conf. Electr. Insul. Dielectr. Phenomena (CEIDP), pp. 13-16, 2008

[78] T. Tanaka, A. Nose, Y. Ohki and Y. Murata, "PD resistance evaluation of LDPE/MgO nanocomposite by a rod-to-plane electrode system", IEEE 8th Intern. Conf. Properties and Applications of Dielectric Materials (ICPADM), pp. 319-322, 2006.

[79] M. Kozako, S. Yamano, R. Kido, Y. Ohki, M. Kohtoh, S. Okabe and T. Tanaka, "Preparation and preliminary characteristic evaluation of epoxy/alumina nanocomposites", Intern Sympos. Electr. Insulating Materials (ISEIM), pp.231-234, 2005.

[80] M. Kozako, N. Fuse, Y. Ohki, T. Okamoto and T. Tanaka, "Surface degradation of polyamide nanocomposites caused by partial discharges using IEC(b) electrodes", IEEE Trans. Dielectr. Electr. Insul, Vol.11, pp.833-839, 2004.

[81] Y. Cao, P. C. Irwin and K. Younsi, "The future of nanodielectrics in the electrical power industry", IEEE Trans. Dielect. Elect. Insul., Vol. 11, pp. 797-807, 2004.

[82] A. H. El-Hag, S. H. Jayaram and E. A. Cherney, "Comparison between Silicone Rubber containing micro- and nano- size silica fillers", IEEE Conf. Electr. Insul. Dielectr. Phenomena (CEIDP), pp. 688-691, 2004. 
[83] T. Tanaka, M. Kozako, N. Fuse and Y. Ohki, "Proposal of a Multi-core Model for polymer nanocomposite dielectrics", IEEE Trans. Dielectr. Electr. Insul, Vol. 12, pp. 669-681, 2005.

[84] T. J. Lewis. "Interfaces are the dominant feature of dielectrics at the nanometric level", IEEE Trans. Dielectr. Electr. Insul, Vol. 11, pp. 739753, 2004.

[85] R. C. Smith, C. Liang, M. Landry, J. K. Nelson and L. S. Schadler, "The mechanisms leading to the useful electrical properties of polymer nanodielectrics", IEEE Trans. Dielectr. Electr. Insul, Vol. 15, pp. 187196, 2008.

[86] J. C. Fothergill, J. K. Nelson and M. Fu, "Dielectric properties of epoxy nanocomposites containing $\mathrm{TiO}_{2}, \mathrm{Al}_{2} \mathrm{O}_{3}$ and $\mathrm{ZnO}$ fillers", IEEE Conf. Electr. Insul. Dielectr. Phenomena (CEIDP), pp. 406-409, 2004.

[87] X. Z. Liu, Z. W. Wu, L. S. Zhong and Z. X. Xu, "Homogenizing effect of electric field caused by nano-powder filled in the converter motor", Electrical Technology, Vol. 2, pp. 7-13, 2004. (in Chinese)

[88] X. Y. Huang, P. K. Jiang and Y.Yin, "Nanoparticle surface modification induced space charge suppression in linear low density polyethylene", Appl. Phys. Lett., Vol. 25, pp. 242905-1-3, 2009.

[89] D. L. Ma, T. A. Hugener, R. W. Siegel, A. Christerson, E. Martensson, C. Onneby and L. S. Schadler, "Influence of nanoparticle surface modification on the electrical behaviour of polyethylene nanocomposites", Nanotechnology, Vol. 16, pp. 724-731, 2005.

[90] G. Chen, J. T. Sadipe, Y. Zhuang, C. Zhang and G. C. Stevens, "Conduction in liner low density polyethylene nanocomposite", IEEE 9th Intern. Conf. Properties and Applications of Dielectric Materials (ICPADM), pp. 845 - 848, Harbin, China, 2009.

This paper is based on a presentation given at the $354^{\text {th }}$ Xiangshan Science Conferences, Beijing, China, 23-25 June 2009.

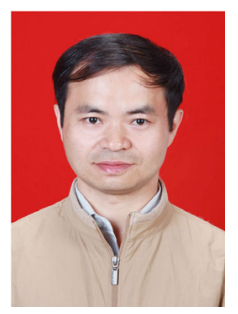

Shengtao Li, (M'96), was born in Sichuan, China, in February, 1963. He received the B.Sc., M.Sc. and Ph.D. degrees in electrical engineering, from Xi'an Jiaotong University in 1983, 1986, and 1990 , respectively. Currently, he is a professor at the State Key Laboratory of Electrical Insulation and Power Equipment in Xi'an Jiaotong University. His research interests include dielectrics and their application, insulating materials and electrical insulation. He can be reached by email at sli@mail.xjtu.edu.cn.

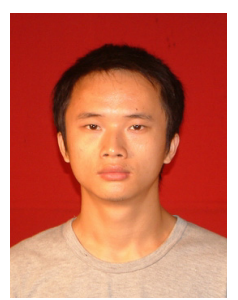

Guilai Yin was born in Jiangxi, China in 1983. He received the B.S in mechanical engineering from Center South University. Currently, he is a graduate student of high voltage and insulation technology in Xi'an Jiaotong University. His main research field is organic nanocomposites and environmentally friendly insulation. He can be reached by email at yg1706@stu.xjtu.edu.cn

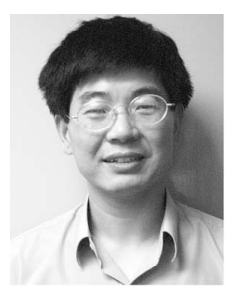

G. Chen was born in China in 1961. He received the B.Eng. and M.Sc. in 1983 and 1986, respectively in electrical engineering from Xi'an Jiaotong University, China. After he obtained the Ph.D. degree in 1990 in electrical engineering from The University of Strathclyde, UK, he joined the University of Southampton as a postdoctoral research fellow and became a senior research fellow subsequently. In 1997 he was appointed as a research Lecturer and was promoted to a Reader in 2002. Over the years, he has developed a wide range of interests in high voltage engineering and electrical properties of materials and published over 100 papers. He is a visiting Professor at Xian Jiaotong University, China. He can be reached by email atgc@ecs.soton.ac.uk

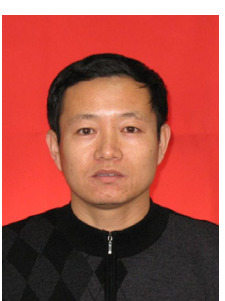

Jianying Li was born in Shaanxi, China in 1972. He received the B.S, M.S and Ph.D. degrees in electrical engineering from Xi'an Jiaotong University, China in 1993, 1996 and 1999. He is now a professor at Xi'an Jiaotong University. His major research fields are high voltage insulation and dielectrics. He can be reached by email at lijy@mail.xjtu.edu.cn

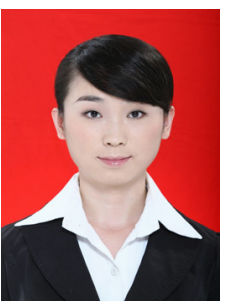

Suna Bai was born in Shanxi, China, in January, 1985. She received the B.Sc. degree in electrical engineering, from Chang'an University in 2007. Currently, she is a graduate student of high voltage and insulation technology in Xi'an Jiaotong University. Her main research field is organic nanocomposites and environmentally friendly insulation. She can be reached by email at bai.suna@stu.xjtu.edu.cn

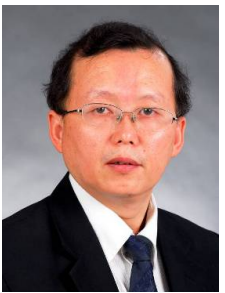

Lisheng Zhong was born in Sichuan, China in 1961. $\mathrm{He}$ received the M.Sc and Ph.D. degrees in electrical engineering, from Xi'an Jiaotong University in 1986 and 1997, respectively. Currently, he is a professor at the State Key Laboratory of Electrical Insulation and Power Equipment in Xi'an Jiaotong University. His research interests include electrical dielectric materials, insulation technology and biological dielectrics. He can be reached by email at lszhong@mail.xjtu.edu.cn.

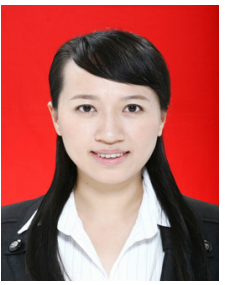

Yunxia Zhang was born in Neimeng, China, in October 1983. She received the B.Sc. degree in electrical engineering, from Xi'an Jiaotong University in 2007. Currently, she is a graduate student of high voltage and insulation technology in Xi'an Jiaotong University. Her main research field is electronic ceramics and nonocomposites. She can be reached by email at zhangyx@stu.xjtu.edu.cn.

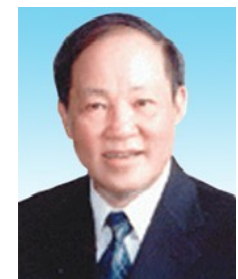

Qingquan Lei was born in Sichuan, China, in July 1938. He graduated from Xi'an Jiaotong University in 1962. He was elected an academician in the Chinese Academy of Engineering in 2003. Now he is a professor of Harbin University of Science and Technology. He conducts teaching and research on basic theory of Insulation technology and its applications. 